\title{
Prognostic Significance of Neutrophil-Lymphocyte Ratio and Platelet-Lymphocyte Ratio in Metastatic Colorectal Cancer
}

Gülcan Bulut ( $\nabla$ gulcanbulut07@gmail.com )

Ege University Faculty of Medicine: Ege Universitesi Tip Fakultesi https://orcid.org/0000-0001-73820972

\section{Zehra Narlı Özdemir}

Ankara City Hospital: Ankara Sehir Hastanesi

\section{Research Article}

Keywords: Metastatic Colorectal cancer, Neutrophil-lymphocyte radio, Platelet-lymphocyte radio, prognosis

Posted Date: February 23rd, 2021

DOI: https://doi.org/10.21203/rs.3.rs-239082/v1

License: (c) (i) This work is licensed under a Creative Commons Attribution 4.0 International License. Read Full License

Version of Record: A version of this preprint was published at Journal of Gastrointestinal Cancer on March 9th, 2021. See the published version at https://doi.org/10.1007/s12029-021-00616-y. 


\section{Abstract}

There are many studies on biomarkers for prognosis in the treatment of metastatic colorectal cancer. Neutrophil-lymphocyte radio (NLR) and Platelet-lymphocyte radio (PLR) are of interest with studies revealing the relationship between inflammatory biomarkers and cancer. Our study is a retrospective file study and the contribution of NLR and PLR to progression-free survival (PFS) and overall survival(OS) before first line chemotherapy was investigated regardless treatment. The cut off values of NLR and TLR were determined using ROC curve analysis. NLR and PLR was divided into two groups according to the cut-off points. OS and PFS associated with NLR and TLR were performed by Kaplan-Meier method. In our study, we could not demonstrate the prognostic potential of pre-treatment NLR and PLR in patients with mCRC treated with first-line chemotherapy. Our study was showed that the use of these biomarkers in $\mathrm{mCRC}$ is limited.

\section{Introduction:}

Colorectal cancer (CRC) is the third most common cancer worldwide. While the incidence and the mortality rate of colorectal cancer has decreased due to effective cancer screening, CRC is still the second most common cause of cancer-related deaths in the Western world (1) and $20 \%$ of patients with CRC have metastases at time of diagnosis (2).

Advances in CRC therapy as combination of chemotherapy with targeted agents and supportive care have led to significant improvement in survival rates for CRC patients. However, metastatic colorectal cancer (mCRC) remains to have poor prognosis with with an approximately 2-year survival (3). A multitude of factors at diagnosis, including clinical parameters (age, performance status, comorbidities), biological properties of the tumor (local growth, distant metastasis, sidedness), molecular factors (KRAS, NRAS, and BRAF mutations) and biochemical markers such as carcinoembryonic antigen, lactate dehydrogenase, platelets, leucocytes, hemoglobin, alkaline phosphatase, albumin have important prognostic impact for outcome in mCRC $(4,5)$. In recent decades, studies provided definitive evidence about the association between inflammation and cancer development $(6,7)$.

The inflammation is essential for tumor microenvironment, and inflammatory cells can affect tumor proliferation, angiogenesis, metastasis, and genetic instability. Lymphocytes, macrophages, and granulocytes are involved in the anti-cancer battle (8). The main cell population in anti-cancer immune response is the population of cytotoxic T lymphocytes (CTLs) (9). Neutrophils may play a crucial role in inflammation driven tumorigenesis (10). Neutrophil population consists of pro- and antitumor subpopulations (11). It is controversy that neutrophil abundance correlates with a better prognosis. (12). Platelets release some tumor growth factors which play a significant role in cancer growth, progression, and metastasizing (13). In previous studies, elevated pretreatment neutrophil-to-lymphocyte ratio (NLR) and platelet-to-lymphocyte ratio (PLR) in peripheral blood were identified as independent prognostic factors. As a result, various studies have suggested that analysis of inflammatory factors could be helpful for predicting survival in cancer, including assessment of inflammatory cells in peripheral blood. 
Fortunately, several parameters for predicting survival in patients with CRC have been identified, including such inflammatory-based prognostic parameters as NLR, PLR, white blood cell count, and platelet count $(14,15)$.

NLR, calculated as neutrophil count divided by lymphocyte count, is the most frequently reported marker and is used in almost every stage of CRC $(14,16,17)$. Increased NLR is associated with worse outcomes and poor response to adjuvant chemotherapy or radiotherapy $(18,19)$. PLR, defined as platelet count divided by lymphocyte count, is also gaining attention in some research (20). It is contradictory whether both indices are associated with first line chemotherapy response in patients with metastatic colorectal disease. Here, we present real-life data about the association of NLR and PLR with survival outcomes in patients with mCRC.

\section{Material And Methods:}

\section{Patients:}

Patients with metastatic colorectal cancer who received treatment at the Defne Hospital, Antakya between January 2010- December 2020, were retrospectively evaluated. Medical records of the hospital were reviewed in terms of age, sex, tumor side, metastasis status as de novo metastasis or at time of relapse, number of metastatic sites, KRAS mutation status as wild and mutant, chemotherapeutic agents, hematological parameters including lymphocyte, thrombocyte, neutrophil.

\section{NLR and TLR:}

NLR was defined the ratio of absolute neutrophil and lymphocyte count within one weeks before initiation of first-line chemotherapy. TLR was defined the ratio of thrombocyte and lymphocyte count within one weeks before the first-line chemotherapy.

NLR was divided into two groups according to the cut-off points $\geq 3.44$ or $<3.44$ as NLR high and low (area under the curve: 0.545 , specificity: 0.5 , sensitivity: 0.585 ). TLR was divided into two groups based on the cut-off points ( $\geq 180.36$ or $<180.36$ ) as TLR high and low (area under the curve: 0.529 , specificity: 0.5 , sensitivity: 0.5 ). The cut off values of NLR and TLR were determined using ROC curve analysis. All the procedures were conducted according to the Declaration of Helsinki, and the study protocol was approved by the Ethics Committee of Mustafa Kemal University, School of Medicine (Hatay, Turkey).

\section{Statistical Analysis:}

Overall survival (OS) and progression free survival (PFS) associated with NLR and TLR were performed by Kaplan-Meier method and log-rank test was used for comparison of survival distribution among groups. Patient age, gender, tumor site, KRAS mutation status, initial chemotherapy, number of metastatic sites and absolute lymphocyte count (ALC) were compared by Chi-square, Fisher's exact and MannWhitney U tests as appropriate. Univariate and multivariate analyzes were performed via a Cox- 
proportional hazards model. SPSS 22.0 (SPSS Inc., Chicago, IL, USA) software was used in all statistical analyses. A $p$ value of $<0.05$ was considered as significant.

\section{Results:}

\section{General Characteristics}

A total of 94 patients, of whom $56(59.6 \%)$ were male and 38 (40.4\%) females, were included. The median age was 64 years (32-84 years). Demographic features of the patients including age, gender, tumor site, KRAS mutation status, initial chemotherapy (oxaliplatine based, irinotecan based and single agent 5 -fluorouracil) and number of metastatic sites were given in table 1 .

Patients were divided into two groups according to NLR as NLR-low and NLR-high. Fifty-four (57.4\%) patients were in NLR-low group and 40 (42.6\%) patients were in NLR-high group. There was no difference between groups in terms of age, gender, tumor site, KRAS mutation status, initial chemotherapy regimen, number of metastatic sites, metastasis status, $p>0.05$ (Table 1). Additionally, patients were grouped according to TLR as TLR-low and TLR- high. There were 47 (\%50) patients in TLR-low group and 47 (50\%) patients in TLR-high group. All demographic features listed in table 1, were similar between TLR-low and TLR-high groups, $p>0.05$.

\section{Survival analysis}

Median overall survival was similar in NLR-low and NLR-high groups, [33.06 \pm 3.01 months $(95 \% \mathrm{Cl} 27.16-$ $38.96)$ vs $32.4 \pm 2.29$ months $(95 \% \mathrm{Cl} 27.9-36.89) ; \mathrm{p}=0.67]$, respectively. Median PFS was $11.2 \pm 0.94$ months (95\% $\mathrm{Cl}$ 9.35-13.04) in NLR-low group and 11.16 \pm 1.46 months (95\% $\mathrm{Cl} 8.3-14.03)$ in NLR-high group, $\mathrm{p}=0.82$ (Figure 1).

There was no difference in terms of OS and PFS between groups TLR-low and TLR-high. Median OS in TLR-low and TLR-high groups were [35.63 \pm 6.07 months ( $95 \% \mathrm{Cl} 23.72-47.54)$ vs $32.4 \pm 2.31$ months (95\% $\mathrm{Cl} 27.86-36.93) ; \mathrm{p}=0.71]$, respectively. Median PFS in TLR-low and TLR-high groups were [12.16 \pm 0.76 months ( $95 \% \mathrm{Cl} 10.67-13.65)$ vs $11.16 \pm 1.37$ months ( $95 \% \mathrm{Cl} 8.46-13.86) ; \mathrm{p}=0.77$ ], respectively (Figure 2 ).

Univariate analysis revealed that NLR and TLR had no effect on the OS and PFS in patients with metastatic colorectal cancer (Table 3). Multivariate analysis confirmed that NLR and TLR were not related with survival outcomes. In our cohort, multivariate analysis also revealed that sex, tumor sites and number of metastases had no impact on the OS and PFS.

\section{Table 1: Demographic features of the patients}




\begin{tabular}{|c|c|c|c|c|c|c|c|}
\hline & $\begin{array}{l}\text { All } \\
\text { Patients } \\
\text { N=94 (\%) }\end{array}$ & $\begin{array}{l}\text { NLR-low } \\
\begin{array}{l}\text { N=54 } \\
(57.4)\end{array}\end{array}$ & $\begin{array}{l}\text { NLR-high } \\
\mathrm{N}=40 \\
(42.6)\end{array}$ & $\mathbf{p}$ & $\begin{array}{l}\text { TLR-low } \\
\begin{array}{l}\mathrm{N}=47 \\
(50)\end{array}\end{array}$ & $\begin{array}{l}\text { TLR- } \\
\text { high } \\
\mathrm{N}=47 \\
(50)\end{array}$ & $\mathbf{p}$ \\
\hline \multicolumn{8}{|l|}{ Age } \\
\hline (median, min-max) & $\begin{array}{l}64(32- \\
84)\end{array}$ & $\begin{array}{l}62.5(32- \\
84)\end{array}$ & $\begin{array}{l}65.5(32- \\
83)\end{array}$ & .9 & $\begin{array}{l}62(34- \\
84)\end{array}$ & $\begin{array}{l}66(32- \\
83)\end{array}$ & .28 \\
\hline \multicolumn{8}{|l|}{ Gender } \\
\hline Male & $56(59.6)$ & $30(55.6)$ & $26(65.0)$ & \multirow[t]{2}{*}{.35} & 27 & $\begin{array}{l}29 \\
(617)\end{array}$ & \multirow[t]{2}{*}{.67} \\
\hline Female & $38(40.4)$ & $24(44.4)$ & $14(35.0)$ & & $\begin{array}{l}20 \\
(42.6)\end{array}$ & $\begin{array}{l}18 \\
(38.3)\end{array}$ & \\
\hline \multicolumn{8}{|l|}{ Tumor site } \\
\hline Right & $24(25.5)$ & $13(24.1)$ & $11(27.5)$ & \multirow[t]{2}{*}{.70} & 11 & $\begin{array}{l}13 \\
(277)\end{array}$ & \multirow[t]{2}{*}{.63} \\
\hline Left & $70(74.5)$ & $41(75.9)$ & $29(72.5)$ & & $\begin{array}{l}36 \\
(76.6)\end{array}$ & $\begin{array}{l}34 \\
(72.3)\end{array}$ & \\
\hline \multicolumn{8}{|c|}{ KRAS mutation status } \\
\hline Wild & $43(45.7)$ & $24(44.4)$ & $19(47.5)$ & \multirow{4}{*}{.62} & $\begin{array}{l}23 \\
(48.9)\end{array}$ & $\begin{array}{l}20 \\
(42.6)\end{array}$ & \multirow[t]{4}{*}{.73} \\
\hline Mutant & $48(51.1)$ & $29(53.7)$ & 19 (47.5) & & \multirow{2}{*}{$\begin{array}{l}23 \\
(48.9)\end{array}$} & \multirow{2}{*}{$\begin{array}{l}25 \\
(53.2)\end{array}$} & \\
\hline \multirow[t]{2}{*}{ Unknown } & $3(3.2)$ & $1(1.9)$ & $2(5.0)$ & & & & \\
\hline & & & & & $1(2.1)$ & $2(4.3)$ & \\
\hline \multicolumn{8}{|l|}{ Initial chemotherapy } \\
\hline Oxaliplatin-based & $48(51.1)$ & $30(55.6)$ & $18(45.0)$ & \multirow[t]{4}{*}{.40} & $\begin{array}{l}23 \\
(489)\end{array}$ & $\begin{array}{l}25 \\
(532)\end{array}$ & \multirow[t]{4}{*}{.90} \\
\hline Irinotecan-based & $43(45.7)$ & $23(42.6)$ & $20(50.0)$ & & \multirow{2}{*}{$\begin{array}{l}22 \\
(46.8)\end{array}$} & \multirow{2}{*}{$\begin{array}{l}21 \\
(44.7)\end{array}$} & \\
\hline \multirow[t]{2}{*}{ Only FU } & $3(3.2)$ & $1(1.9)$ & $2(5.0)$ & & & & \\
\hline & & & & & $2(4.3)$ & $1(2.1)$ & \\
\hline \multicolumn{8}{|c|}{$\begin{array}{l}\text { Number of metastatic } \\
\text { sites }\end{array}$} \\
\hline \multirow{2}{*}{ (1) } & 39 (41.5) & $21(38.9)$ & $18(45.0)$ & \multirow{4}{*}{.14} & $\begin{array}{l}18 \\
(38.3)\end{array}$ & $\begin{array}{l}21 \\
(44.7)\end{array}$ & \multirow{4}{*}{.70} \\
\hline & 38 (40.4) & $26(48.1)$ & $12(30.0)$ & & & & \\
\hline \multirow{2}{*}{$>2$} & $17(18.1)$ & $7(13.0)$ & $10(25.0)$ & & $(44.7)$ & $(36.2)$ & \\
\hline & & & & & $8(17.0)$ & $9(19.1)$ & \\
\hline
\end{tabular}


At time of relapse

$38(40.4)$

$20(37.0)$

$18(45.0)$

.43

18

20

De novo

$56(59.6)$

$34(63.0)$

$22(55.0)$

(38.3)

(42.6)

.67

$29 \quad 27$

(61.7) (57.4)

NLR: Neutrophil-lymphocyte radio, PLR: Platelet- lymphocyte radio

Table 2. Univariate analysis for OS and PFS

\begin{tabular}{|llrlll|}
\hline Variables & Overall Survival & & Progression free survival & \\
& $\begin{array}{l}\text { Univariate analysis, HR } \\
(95 \% \mathrm{Cl})\end{array}$ & $\mathrm{p}$ & $\begin{array}{l}\text { Univariate analysis, HR } \\
(95 \% \mathrm{Cl})\end{array}$ & $\mathrm{p}$ \\
\hline NLR level $(<3.44$ and $\geq 3.44)$ & $0.89(0.53-1.50)$ & .67 & $0.95(0.60-1.49)$ & .82 \\
\hline $\begin{array}{l}\text { TLR level }(<180.36 \text { and } \\
\geq 180.36)\end{array}$ & $1.10(0.66-1.82)$ & .71 & $0.93(0.60-1.46)$ & .77 \\
\hline
\end{tabular}

NLR: Neutrophil-lymphocyte radio , PLR: Platelet- lymphocyte radio

Table 3: Multivariate analysis for OS and PFS

\begin{tabular}{|llrll|}
\hline Variables & Overall Survival & & Progression free survival & \\
& $\begin{array}{l}\text { Univariate analysis, HR } \\
(95 \% \mathrm{Cl})\end{array}$ & $p$ & $\begin{array}{l}\text { Univariate analysis, HR } \\
(95 \% \mathrm{Cl})\end{array}$ & $\mathrm{p}$ \\
\hline NLR level $(<3.44$ and $\geq 3.44)$ & $0.84(0.42-1.66)$ & .62 & $1.12(0.62-2.02)$ & .68 \\
\hline $\begin{array}{l}\text { TLR level }(<180.36 \text { and } \\
\geq 180.36)\end{array}$ & $1.18(0.63-2.22)$ & .60 & $0.90(0.53-1.54)$ & .71 \\
\hline Gender (male and female) & $0.71(0.39-1.27)$ & .25 & $0.79(0.49-1.26)$ & .32 \\
\hline $\begin{array}{l}\text { Tumor site (right and left) } \\
\text { Number of metastases }\end{array}$ & $1.1(0.60-1.99)$ & .75 & $1.31(0.76-2.25)$ & .32 \\
$(1$ and 2 and $>2)$ & $0.68(0.32-1.43)$ & .52 & $0.74(0.38-1.43)$ & .63 \\
\hline
\end{tabular}

NLR: Neutrophil-lymphocyte radio , PLR: Platelet- lymphocyte radio; OS : Overall Survey, PFS : Progression free survival

\section{Discussion:}

The prognostic significance of the NLR and PLR have been researched in many tumors $(21,22)$. Previous studies claimed that increased systemic inflammatory markers such as NLR and PLR are associated with poor prognosis in operated colorectal cancer (23). However, the effect of these markers on chemotherapy 
efficiency is not well known in metastatic colorectal cancer. In our study, we analyzed the association between pre-treatment NLR and PLR levels with chemotherapy response in patients with $\mathrm{mCRC}$.

Previous studies used similar NLR cut-offs, such as 2 or 5 , to differentiate patients into low- and high-risk groups $(24,25)$. However, we defined a more accurate cut-off level using the ROC curve analysis. We used the 3.44 value to categorize our patients into NLR low-risk group ( $<3.44)$ and NLR high-risk group $(\geq 3.44)$. In our cohort, patients with low NLR did not have better OS and PFS (PFS; 11.16 months vs 11.2 months \& OS; 33.06 months vs 32.4 months).

Likewise, reports about the association of PLR with survival outcomes used PLR cut-offs, such as 150 or 200 , that usually differentiate patients into low- and high-risk groups (26). We used the 180.3 value, estimated with ROC curve analysis, to categorize patients into a PLR low-risk group (<180.3) and PLR high-risk group ( $\geq 180.3$ ). OS and PFS were similar in PLR low-risk group and high-risk group (PFS; 12.16 months vs 11.16 months, OS; 35.6 months vs 32.4 months).

Dogan et al investigated association between NLR, PLR levels and survival outcomes in patients who received the targeted therapy as first line treatment. They showed that NLR and PLR were related with better PFS only in the bevacizumab arm but did not predict OS and PFS in patients who received antiEGFR treatments (27). G. Nogueira-Costa et al found that NLR was associated with both better PFS and OS. They claimed that the NLR predicted treatment response, but their study was done with a low cut-off value for NLR (28). Therefore, it can be considered that our patient cohort had relatively poor prognosis due to higher cut-off value for NLR compared with literature. Yang et al reported that NLR is a negative predictive marker for PFS and OS in metastatic colorectal patients treated with cetuximab, for which 2.34 was accepted as a cut-off value. (29). Matsuda et al studied prognostic effects of NLR and PLR in patients with CRCm treated with aflibercept by using 3.82 cut-off value for NLR and 193.2 for PLR. They reported only PLR was a prognostic biomarker in patients with CRCm (26). We suggest that as the NLR cut-off value decreases, the probability of the NLR predicting OS and PFS may increase.

The major limitations of our study are its retrospective nature, small sample size, and single-centre, single-arm turkey-based cohort design. However, it provides a real-life data about the prognostic significance of NLR and PLR that assessed just before the first-line therapy, in patients with CRCm. The validity of the applied NLR and PLR cut-off, the median value and superior cut-off, which is an absolute value, should be investigated in a future prospective study with a larger sample size.

\section{Conclusion:}

In our study, we could not demonstrate the prognostic potential of pre-treatment NLR and PLR in patients with $\mathrm{mCRC}$ treated with first-line chemotherapy. We suggest that these markers have limited prognostic value in patients with $\mathrm{CRCm}$.

\section{References:}


1. Ferlay J, Soerjomataram I, Dikshit R at. al. Cancer incidence and mortality worldwide: sources, methods and major patterns in GLOBOCAN 2012. Int J Cancer 136: E359-386, 2015

2. Van Cutsem E, Cervantes A, Nordlinger B at. al. Metastatic colorectal cancer: ESMO clinical practice guidelines for diagnosis, treatment and follow-up. Ann Oncol. 2014;25 Suppl 3:iii1-9.

3. Hamers PAH, Elferink MAG, Stellato RK et al. Informing metastatic colorectal cancer patients by quantifying multiple scenarios for survival time based on real-life data. Int J Cancer. 2020.

4. Stein A, Bokemeyer C. How to select the optimal treatment for first line metastatic colorectal cancer. World J Gastroenterol. 2014;20:899-907.

5. De Divitiis C, Nasti G, Montano M at. al. Prognostic and predictive response factors in colorectal cancer patients: between hope and reality. World J Gastroenterol. 2014;20:15049-59.

6. Coussens LM, Werb Z. Inflammation and cancer. Nature. 2002;420:860-7.

7. Lu H, Ou yang W, Huang C. Inflammation, a key event in cancer development. Mol Cancer Res. 2006;4:221-33.

8. Tartour E, Zitvogel L. Lung cancer: potential targets for immunotherapy. Lancet Respir Med. 2013;1:551-63.

9. Aerts JG, Hegmans JP Tumor-specific cytotoxic T cells are crucial for efficacy of immunomodulatory antibodies in patients with lung cancer. Cancer Res. 2013 Apr 15; 73(8):2381-8.

10. Shang K, Bai YP, Wang $C$ at. al. Crucial involvement of tumor-associated neutrophils in the regulation of chronic colitis-associated carcinogenesis in mice.PLoS One. 2012; 7(12):e51848.

11. Sagiv JY, Michaeli J, Assi S at. al. Phenotypic diversity and plasticity in circulating neutrophil subpopulations in cancer. Cell Rep. 2015 Feb 3; 10(4):562-73.

12. Sionov RV, Fridlender ZG, Granot Z. The Multifaceted Roles Neutrophils Play in the Tumor Microenvironment. Cancer Microenviron. 2015 Dec; 8(3):125-58.

13. Pilatova K, Zdrazilova-Dubska L, Klement GL The role of platelets in tumour growth. Klin Onkol. 2012; 25 Suppl 20:2S50-7.

14. Malietzis $\mathrm{G}$, Giacometti $\mathrm{M}, \mathrm{Kennedy} \mathrm{RH}$ at. al. The emerging role of neutrophil to lymphocyte ratio in determining colorectal cancer treatment outcomes: a systematic review and meta-analysis. Ann Surg Oncol. 2014;21:3938-46.

15. Feng JF, Huang Y, Chen QX. The combination of platelet count and neutrophil lymphocyte ratio is a predictive factor in patients with esophageal squamous cell carcinoma. Transl Oncol. 2014;7:632-7.

16. Galizia G, Lieto E, Zamboli A at.al. Neutrophil to lymphocyte ratio is a strong predictor of tumor recurrence in early colon cancers: a propensity score-matched analysis. Surgery. 2015;158:112-20.

17. Shin JS, Suh KW, Oh SY. Preoperative neutrophil to lymphocyte ratio predicts survival in patients with T1-2N0 colorectal cancer. J Surg Oncol. 2015;112:654-7

18. Krauthamer M, Rouvinov K, Ariad S at. al. A study of inflammation-based predictors of tumor response to neoadjuvant chemoradiotherapy for locally advanced rectal cancer. Oncology. 2013;85:27-32. 
19. Kim IY, You SH, Kim YW. Neutrophil-lymphocyte ratio predicts pathologic tumor response and survival after preoperative chemoradiation for rectal cancer. BMC Surg. 2014;14:94.

20. Pichler M, Absenger G, Stotz M et al. The elevated preoperative platelet to lymphocyte ratio predicts decreased time to recurrence in colon cancer patients. Am J Surg. 2014;208:210-4.

21. Zhang Y, Jiang C, Li J, Sun J, Qu X. Prognostic significance of preoperative neutrophil/lymphocyte ratio and nplatelet/lymphocyte ratio in patients with gall bladder carcinoma. Clin Transl Oncol 2015;17:810-8.

22. Bozkurt $\mathrm{O}$, Karaca $\mathrm{H}$, Berk $\mathrm{V}$ et al. Predicting the role of the pretreatment neutrophil to lymphocyte ratio in the survival of early triple- negative breast cancer patients. JBUON 2015;20:1432-9.

23. Roxburgh CSD, McMillan D. Role of systemic inflammatory response in predicting survival in patients with primary operable cancer. Future Oncol 2010;6:149-63.

24. Chua W, Charles KA, Baracos VE, Clarke SJ. Neutrophil/lymphocyte ratio predicts chemotherapy outcomes in patients with advanced colorectal cancer. $\mathrm{Br} J$ Cancer. 2011;104:1288-95.

25. Dell'Aquila $E$, Cremolini $C$ et al. Prognostic and predictive role of neutrophil/lymphocytes ratio in metastatic colorectal cancer: a retrospective analysis of the tribe study by gono. Ann Oncol. 2018;29:924-30.

26. Akıhısa Matsuda, Takeshi Yamada, Satoshı Matsuda at. al. Prognostic Role of the Platelet-toLymphocyte Ratio for Patients With Metastatic Colorectal Cancer Treated With Aflibercept. In Vivo. 2020 Sep-Oct; 34(5): 2667-2673.

27. Ender Dogan, Oktay Bozkurt, Teoman Sakalar at. al. Impact of neutrophil-lymphocyte and plateletlymphocyte ratio on antiEGFR and bevacizumab efficacy in metastatic colorectal cancer. JBUON 2019; 24(5): 1861-1869

28. G. Nogueira-Costa, I. Fernandes, R. Gameiro at. al. Prognostic utility of neutrophil-to-lymphocyte ratio in patients with metastatic colorectal cancer treated using different modalities. Curr Oncol. 2020 Oct; 27(5): 237-243.

29. Yang J, Guo X, Wang M, Ma X, Ye X, Lin P. Pre-treatment inflammatory indexes as predictors of survival and cetuximab efficacy in metastatic colorectal cancer patients with wild-type RAS. Sci Rep 2017;7:17166.

\section{Figures}




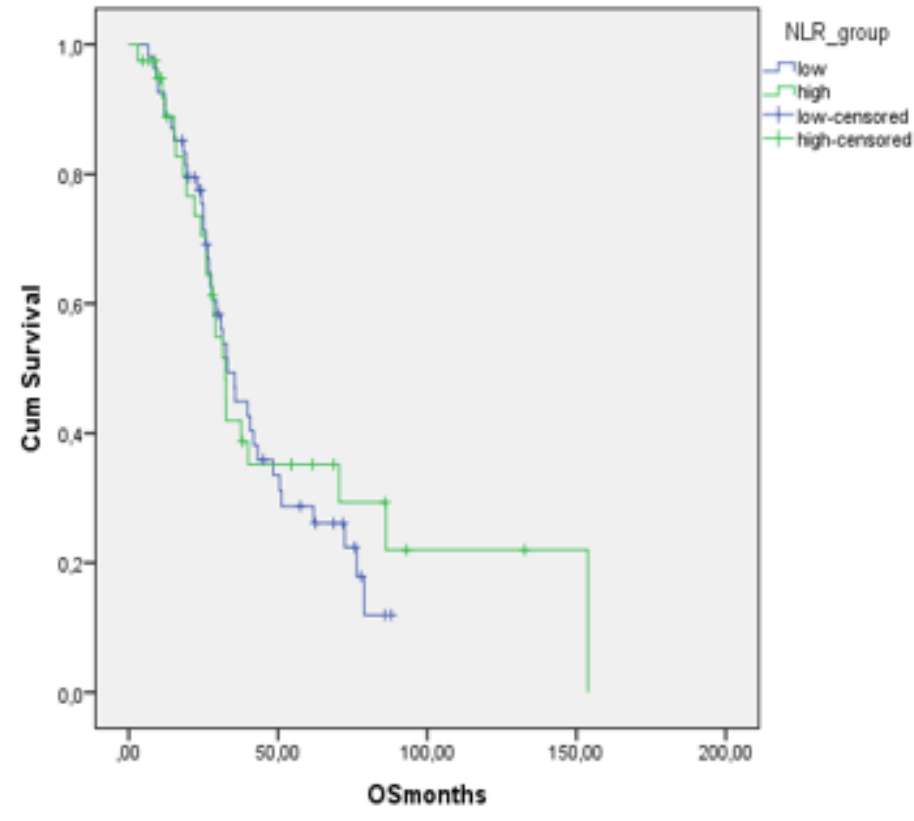

Log rank:0.67

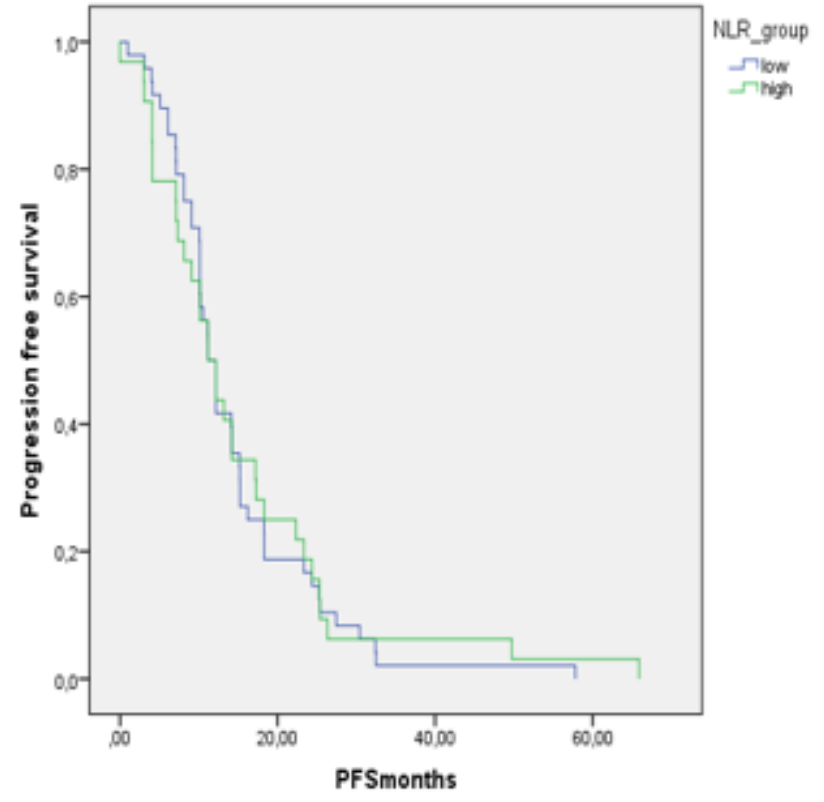

Log rank:0.82

\section{Figure 1}

Association between NLR status and survival analysis.

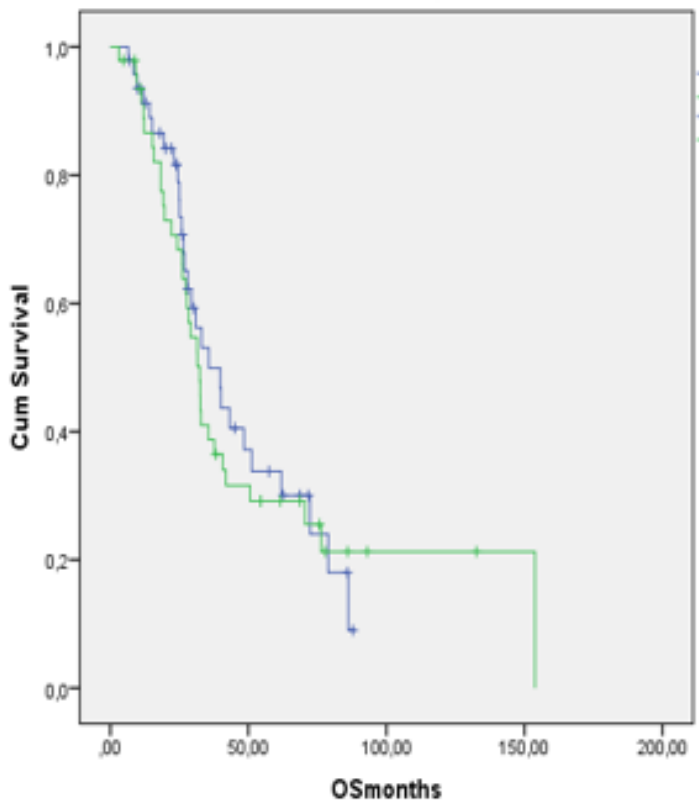

Log rank:0.71

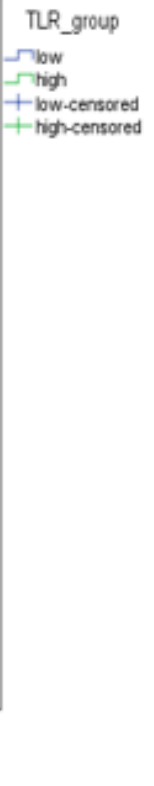

Figure 2

Association between TLR status and survival analysis.

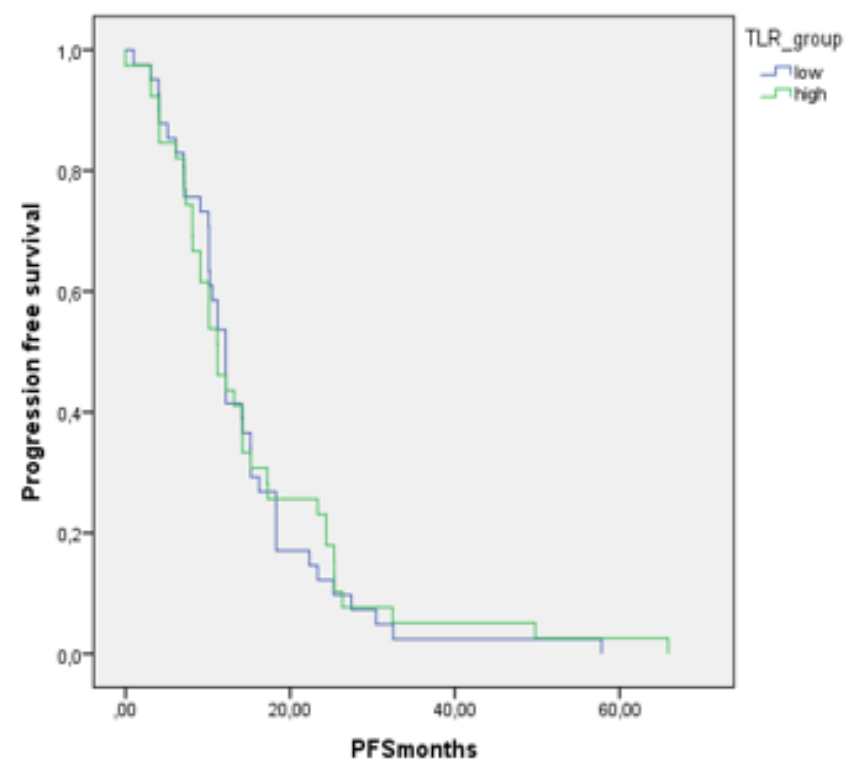

Log rank:0.77 